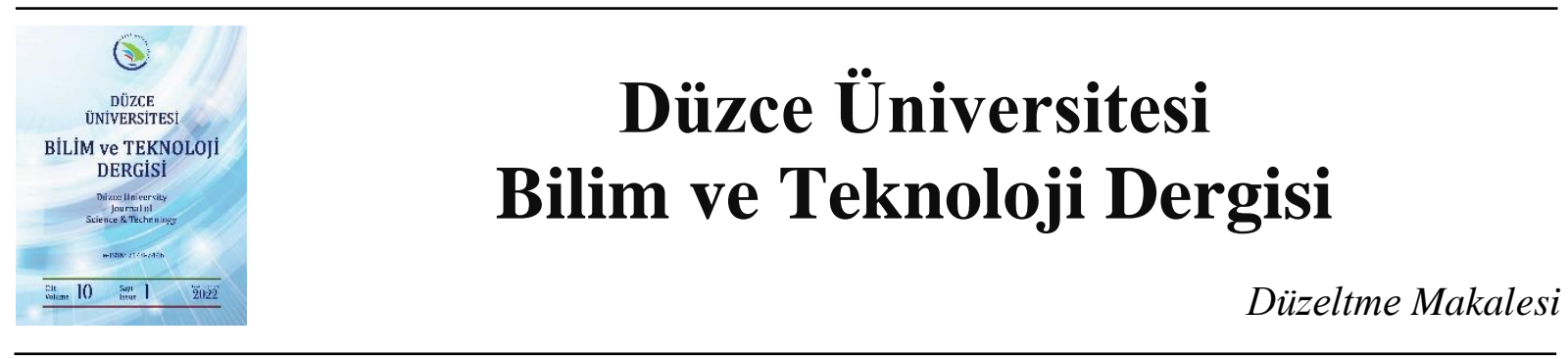

\section{Düzeltme: Mersin İlindeki Küçük ve Orta Ölçekli Mobilya İşletmelerinde Hammadde Sorunu Üzerine Bir Araştırma}

\author{
Hasan SERIN $^{\mathrm{a}, *}$, (D) Mehmet CEYHAN ${ }^{\mathrm{b}}$ \\ ${ }^{a}$ Orman Endüstri Mühendisliği Bölümü, Orman Fakültesi, Kahramanmaraş Sütçü İmam Üniversitesi, \\ Kahramanmaraş, TÜRKİYE \\ ${ }^{b}$ Orman Endüstri Mühendisliği Bölümü, Fen Bilimleri Enstitüsü, Kahramanmaraş Sütçü İmam Üniversitesi, \\ Kahramanmaraş, TÜRKIYYE \\ * Sorumlu yazarin e-posta adresi: hasanserin@ksu.edu.tr
}

DOI: 10.29130/dubited.1065410

\begin{abstract}
$\underline{\mathrm{O} Z}$
Ana faaliyet konusu üretim olan mobilya işletmeleri temel olarak orman ürünlerini hammadde olarak kullanmaktadırlar. Masif odun, liflevha, yongalevha ve tabakalı ağaç malzeme üretim sürecine giren önemli hammadde bileşenlerindendir. $\mathrm{Bu}$ hammaddelerin yetersizliği ve özel tüketim alanlarının oluşması mobilya işletmeleri için hammadde sorunlarını ortaya çıkarmıştır. Bu çalışmada Mersin ilindeki küçük ve orta ölçekli mobilya işletmelerinin karşılaştıkları hammadde sorunları araştırılmıştır. Çalışma kapsamında işletmelerin hammadde temin problemleri, hammadde stokları, hammadde öncelikleri, en fazla kullandıkları hammaddeler, hammadde kullanım amaçları, çeşitli hammadde türlerini kullanma ve kullanmama nedenleri, hammadde sipariş süreçleri ve hammadde Ar-Ge faaliyetleri irdelenmiştir. Bu çalışmanın sonucunda mobilya işletmelerinin hammadde tedarik problemleriyle ilgili genelde sorun yaşamadıklarını ifade ederken, sermaye yetersizliği gibi birkaç sebepten dolayı hammadde stokundan kaçınıldığı ve firmaların \%95'i siparişe yönelik üretim yaptığ ortaya çıkmıştır.
\end{abstract}

Düzeltme: Düzce Üniversitesi Bilim ve Teknoloji dergisinin 2020 8(1) sayısının 258-263 sayfalarında yayınlanan "Mersin ilindeki küçük ve orta ölçekli mobilya işletmelerinde hammadde sorunu üzerine bir araştırma" adlı makalenin yazarlarında değişiklik yapılmıştır. Ayrıca desteklenen proje hakkında bilgi ve teşekkür yazısı eklenmiştir.

Anahtar Kelimeler: Mobilya Işsletmeleri, Hammadde, Anket, Türkiye

\section{Erratum: An Investigation on Problem of Raw Material at Small and Medium Sized Furniture Firms in Mersin Province, Turkey}

\begin{abstract}
Firms of furniture which their basic events are production essentially use products of forest as a raw material. Glued laminated timber, fiberboard, particleboard, and solid wood are significant raw material components in process of manufacture. Lack of these raw materials and generating of particular consumption fields have found out problems of raw material for furniture firms. In this study, problems of raw material that small and medium sized furniture firms in Mersin province, Turkey are investigated. At this research, certain issues are analyzed such as marketing, raw material stocks, raw material problems, usually used raw materials, intended use of raw
\end{abstract}


materials. As results of this study, these are expressed that furniture firms don't have problems of raw material supply, can't keep out stock of raw material because of several reasons clearly undercapitalization and $95,8 \%$ of firms product in reference to order.

Erratum: The authors of the article "An investigation on problem of raw material at small and medium sized furniture firms in Mersin Province" published in pages of 258-263 in Duzce University Science and Technology Journal 2020; 8(1) issue has been changed. Also, the information about supported project and acknowledgement have been added.

Keywords: Furniture Firms, Rawmaterial, Survey, Turkey

\section{GIRIS}

Mobilya endüstrisinde bulunan hammaddeler kaplama, yonga levha, kereste, kontrplak, lif levha gibi malzemelerden oluşmaktadır $[1,2]$. Seri üretim yapan firmaların sayısındaki artış masif ahşap malzemenin kullanımını azaltmakta, alternatif orman ürünlerine olan talebi artırmaktadır. 2015 yılında mobilya sektöründe yaklaşık 16 milyar liralık üretim gerçekleştirilmiştir. Sektörün mobilya üretim miktarı ile ilgili son 2 yıldır veri açıklanmamıştır. Ancak, 10. Kalkınma Planı gelecek öngörülerinde üretim miktarı 2016 yılı için 16,3 milyar, 2017 için 19, 2018 yılı içinse 22 milyar lira olarak tahmin edilmiştir [7]. Panel levha üreticilerinin yaşadıkları üretim zorlukları (yurtdışından odun cipsi ve tomruk ithalatı ile ayrıca tutkal gibi yardımcı maddelerin yüksek fiyatlı olması gibi) işletme maliyetlerini artırmakta ve dolayısıyla kimi üreticiler düşük kaliteli üretime yönelmektedirler. Bu da tedarikçi konumdaki mobilya firmalarının son ürün kalitesini düşürmekte ve rekabet üstünlüğü yakalamasına engel oluşturmaktadır [3].

Orman endüstrisinde önemi olan kereste marangozlukla inşaatta kullanılan ve ağaç gövdelerinin boyuna biçilmesiyle elde edilen malzemelerdir. Türkiye'de özel sektör işletmelerinde kereste üretimi yapılmakta olup özel sektördeki işletmelerin yaklaşık \%12'si parke üretimi ve kereste yapmaktadır. Modern teknoloji tekniğiyle işletmelerden bazıları üretim yaparken büyük bir çoğunluğu ise düşük kapasiteli makinelerle atölye düzeyinde üretim gerçekleştirmektedir $[4,5]$.

Sanayi sektörü üretim faaliyetlerini gerçekleştiren üç sektörden biri olmaktadır. Hammadde ve ara malların belli bir prosesten geçilerek her türlü ürünün elde edilmesi faaliyeti olarak tanımlanabilmektedir $[10,11]$. Türkiye imalat sanayi içerisinde yer alan orman ürünleri firmaları, $\% 25$ oranında bir paya sahip olmaktadır ve istihdam aldığı pay ise \%10 olarak belirtilmektedir [9, 12]. Orman ürünleri firmaları; finansman sıkıntısı, talep yetersizliği, pazarlamada yaşanan sorunlar gibi birçok engel ile karşlaşmakta ve özelliklede hammadde temini ile ilgili problemlerle yüzleşmek sorunda kalmaktadırlar [8].

\section{MATERYAL VE METOD}

$\mathrm{Bu}$ çalışmada mobilya endüstrisinde hammadde tercihleri ve hammadde tedarik problemlerini belirlemek için Mersin ilindeki mobilya işletmeleri seçilmiştir. Mersin ilindeki mobilya işletmelerinin benzerlik ve farklılıkları, hammadde tercihleri ve hammadde tedarik problemleri açısından araştırılmıştır. Hukuki yapılarına göre araştırmak için hazırlanan anket formları ile yüz yüze görüşme metodu uygulanmıştır.

Hammadde tercihleri ve yaşanan hammadde problemlerini araştırmak için 29 adet soru içeren bir anket formu oluşturulmuştur. Bu anket formu işletmeyi tanıtıcı, hammadde öncelikleri, kullanım amaçları, çeşitli hammaddelerin kullanılma ve kullanılmama nedenleri, hammadde siparişleri gibi sorulardan oluşmaktadır. Elde edilen anket formları değerlendirmeye alındıktan sonra verilerin işlenmesi için SPSS (Statistical Package for the Social Sciences) istatistik paket programına veriler girilmiştir. Çapraz tablolar ve ki kare testi uygulanmıştır. 


\section{BULGULAR}

Mersin ilindeki küçük ve orta ölçekli mobilya işletmelerine, yüz yüze görüşülerek elde edilen anketlerden SPSS veri girişinden sonra istatistiksel analiz sonuçları aşağıda sunulmuştur.

Tablo 1. Hammadde temin problemi

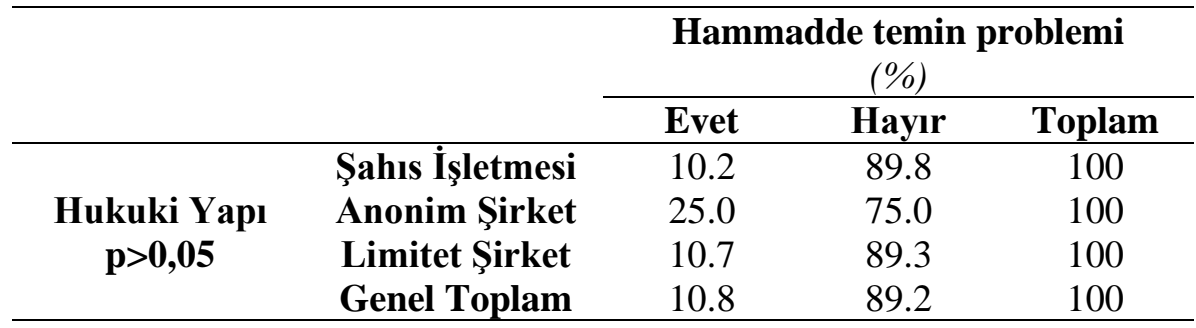

\%95 güven düzeyinde yapılan $\chi^{2}$ testi ile işletmelerin hammadde temin problemleri karşıllaştırılmış ve istatistiksel analizden elde edilen çapraz tablo sonuçları Tablo 1'de verilmiştir. Sonuçlara göre hukuki yapıları açısından işletmeler arasında anlamlı farklılıklar bulunmamaktadır. Sonuçlara göre şahıs işletmelerinin \%89,8'lik kısmı, anonim şirketlerin \%75'lik kısmı ve limitet şirketlerin \%89,3'lük kısmı hammadde temin problemi yaşamamaktadırlar. Anonim şirketlerin \%25'lik kısmı, limitet şirketlerin $\% 10,7^{\prime}$ lik kısmı ve şahıs işletmelerinin \%10,2'lik kısmı ise hammadde temin problemi yaşadıklarını belirmişlerdir.

Tablo 2. Hammadde stoku bulundurma

\begin{tabular}{ccccc}
\hline & & \multicolumn{3}{c}{ Hammadde stoku bulundurma } \\
\cline { 3 - 5 } & & Evet & Hayır & Toplam \\
\hline \multirow{3}{*}{ Hukuki Yapı } & Şahıs İşletmesi & 12.5 & 87.5 & 100 \\
p<0,05 & Anonim Şirket & 75 & 25 & 100 \\
& Limitet Şirket & 42.9 & 57.1 & 100 \\
& Genel Toplam & 21.7 & 78.3 & 100 \\
\hline
\end{tabular}

Tablo 2'ye göre hukuki yapıları açısından işletmeler arasında anlamlı farklılıklar vardır. Sonuçlara göre şahıs işletmelerinin $\% 87,5$ 'i ve limitet şirketlerin $\% 57,1$ 'i hammadde stoku bulundurmazken; anonim şirketlerin $\% 75$ 'i ve limitet şirketlerin \%42,9'u hammadde stoku yaptıklarını belirtmişlerdir.

Tablo 3. Hammadde tercih öncelikleri

\begin{tabular}{ccc}
\hline & $\mathbf{N}$ & $\begin{array}{c}\text { Oran } \\
(\%)\end{array}$ \\
\hline Fiyat & 37 & 30.8 \\
Kalite & 79 & 65.8 \\
Miktar & 2 & 1.7 \\
Zaman & 2 & 1.7 \\
Toplam & 120 & 100 \\
\hline
\end{tabular}

İşletmelerin hammadde öncelikleri Tablo 3 'te gösterilmektedir. Çalışma kapsamındaki işletmelerin $\% 65,8$ 'i hammadde tedarik sürecinde kaliteye öncelik verirken, $\% 30,8$ 'i fiyatın hammadde kararlarını etkilediğini belirtmişlerdir. Miktar ve zaman unsurları ise işletmelerin \%1,7'şer kısmı tarafından öncelik verilmektedir. Hammaddenin boyutu ise hiçbir işletme tarafından önemli bulunmamıştır. 
Tablo 4. Yeterli hammadde stoku yapamama nedenleri

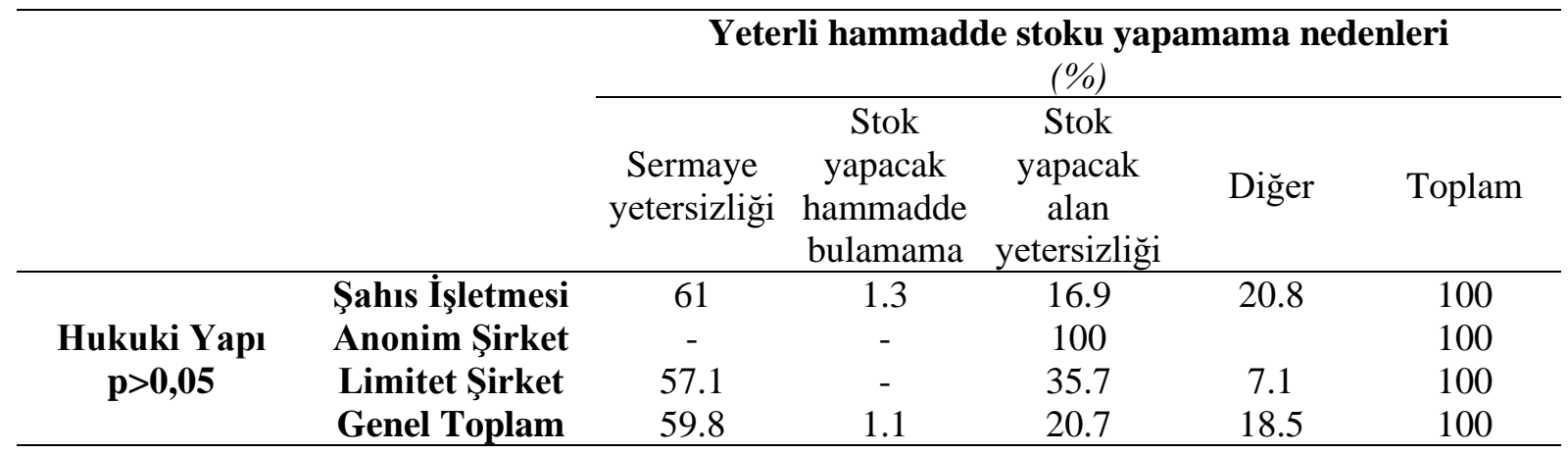

Tablo 4'e göre hukuki yapıları açısından işletmeler arasında anlamlı farklılıklar bulunmaktadır. Sonuçlara göre anonim şirketlerin tamamı stok yapacak alan yetersizliğini ifade ederken; şahıs işletmelerinin \%61'i ile limitet şirketlerin \%57,1'i sermaye yetersizliğinden dolayı hammadde stoku yapamadıklarını belirtmişlerdir. Genel toplama göre ise mobilya işletmelerinin \%59,8'i sermaye yetersizliğini, \%20,7'si stok yapacak alan yetersizliğini, \%18,5'i diğer etkenleri ve \%1,1'i stok yapacak hammadde bulamamalarını neden olarak göstermiştir.

Tablo 5. Isşletmelerin üretim şekilleri

\begin{tabular}{ccccccc}
\hline & & \multicolumn{5}{c}{ İşletmelerin üretim şekilleri } \\
\cline { 3 - 6 } & & $\begin{array}{c}\text { Siparişe } \\
\text { göre üretim }\end{array}$ & $\begin{array}{c}\text { Pazara } \\
\text { dönük } \\
\text { üretim }\end{array}$ & Seri üretim & Diğer & Toplam \\
\cline { 3 - 6 } & Şahıs İşletmesi & 100 & - & - & - & 100 \\
Hukuki Yapı & Anonim Şirket & 75 & 25 & - & - & 100 \\
& Limitet Şirket & 85.7 & 7.1 & 3.6 & 3.6 & 100 \\
& Genel Toplam & 95.8 & 2.5 & 0.8 & 0.8 & 100 \\
\hline
\end{tabular}

Tablo 5'e göre hukuki yapıları açısından işletmeler arasında anlamlı farklılıklar vardır. Sonuçlara göre şahıs işletmelerinin \%100'ü, limitet şirketlerin \%85,7'si ve anonim şirketlerin \%75'i siparişe göre üretim yaptıklarını belirtmişlerdir. Ayrıca anonim şirketlerin $\% 25$ 'i pazara dönük üretim şeklini benimsemişlerdir. $\mathrm{Bu}$ anlamlı farklılığın analizi için Duncan testi yapıldığında ise en yüksek ortalamaya sahip şahıs işletmelerinin A grubunda, limitet şirket ile anonim şirketlerin ise B grubunda yer aldıkları görülmüştür. Genel anlamda ise işletmelerin \%95,8'i siparişe göre üretim yaptıkları görülmektedir.

Tablo 6. İşletmelerin üretim şekilleri

\begin{tabular}{ccccccc}
\hline & \multicolumn{5}{c}{ En çok kullanılan hammadde } \\
\cline { 3 - 6 } & & $\begin{array}{c}\text { Sert odun } \\
\text { kerestesi }\end{array}$ & $\begin{array}{c}\text { Yumuşak } \\
\text { odun } \\
\text { kerestesi }\end{array}$ & MDF & Yonga levha & Toplam \\
\cline { 3 - 7 } & Şahıs İşletmesi & 9.1 & 4.5 & 84.1 & 2.3 & 100 \\
Hukuki Yapı & Anonim Şirket & 25 & & 50 & 25 & 100 \\
p $>\mathbf{0 , 0 5}$ & Limitet Şirket & 10.7 & & 78.6 & 10.7 & 100 \\
& Genel Toplam & 10 & 3.3 & 81.7 & 5 & 100 \\
\hline
\end{tabular}

İşletmelerin en çok kullanılan hammadde sorusuna verdikleri cevaplar $\% 95$ güven düzeyinde yapılan $\chi^{2}$ testi ile karşılaştırılmış ve elde edilen çapraz tablo sonuçları Tablo 6'da verilmiştir. Çizelge 6'ya göre hukuki yapıları açısından işletmeler arasında anlamlı farklılıklar bulunmamaktadır. Sonuçlara 
göre şahıs işletmelerinin \%84,1'i, limitet şirketlerin \%78,6's1 ve anonim şirketlerin \%50'si MDF kullandıklarını belirtmişlerdir. Ayrıca anonim şirketlerin \%25'i sert odun kerestesi, \%25'i de yonga levha kullanmaktadırlar. Bu anlamlı farklılığın analizi için Duncan testi yapıldığında ise en yüksek ortalamaya sahip anonim ve limitet şirketlerin A grubunda, şahıs işletmelerinin ise B grubunda yer aldıkları görülmüştür. Genel anlamda ise işletmelerin \%81,7'si MDF, \%10'u sert odun kerestesi, \%5'i yonga levha ve \%3,3’ü de yumuşak odun kerestesi kullandıklarını ifade etmişlerdir.

\section{IV.SONUC}

Günümüz bilgi ve iletişim çağında mobilya işletmelerinin geneli Tablo 1'de gösterildiği üzere hammadde tedarik problemi yaşamamaktadır. Rekabet unsurunun önemi göz önünde tutulduğunda müşterileriyle daha sıkı bağlar kurmak isteyen ve müşteri memnuniyetini önceliği yapan mobilya işletmeleri, firmanın yenilikçilik anlayışının tedarik zinciri yönetimini etkilemesi dikkate alındığında [6] hammadde tedarikinde kaliteyi ilk sıraya koymaktadır. Miktar, zaman ve fiyat faktörlerini kaliteden sonra bir yere koymaktadırlar.

Akyüz ve arkadaşları (2003), yaptıkları çalışmada mobilya üretimi ile ilgilenen işletmelerin büyük çoğunlukla MDF kullanımını tercih ettiklerini belirtmişlerdir. Bunun nedeni ise MDF'deki çalışma özelliklerinin az oluşu ve direnç özelliklerinde görülen yükseklik olduğunu ifade etmişlerdir. Yonga levhayı öncelikli olarak kullanan işletmelerin temel tercih nedeninin ise fiyatının düşük olmasından kaynaklandığını belirtmişlerdir. Mobilya işletmelerinin büyük çoğunluğu $(\% 81,7)$ hammadde olarak MDF kullanmaktadır. Yurdakul ve arkadaşlarının (2013)'nin çalışması mobilya endüstrisinin en fazla ithal ettiği hammadde kalemlerini OSB, kereste ve kaplama olarak göstermiştir. Gerek faaliyet gösterilen bölgede gerekse ulusal düzeyde MDF üretiminin mevcut olması işletmelere ekstra bir avantaj sağlayabilecektir.

Son olarak mobilya işletmelerinin büyük çoğunluğunun hammadde üzerine Ar-Ge çalışanı istihdam etmedikleri gözlenmiştir. İlk etapta üretim veya pazarlama departmanına Ar-Ge faaliyetleri yapacak birinin alınması ve sonraki aşamalarda sadece Ar-Ge ile ilgilenen birimin kullanılması işletmenin iç tedarik zincirinin etkinliğini arttırabilecektir. Ayrıca gerek görüldüğü yerlerde üniversiteler ve araştırma merkezlerinden destek alınması da verimlilik ve etkinliği arttırmada fayda sağlayabilecektir.

TEŞEKKÜR: Bu çalışma Kahramanmaraş Sütçü İmam Üniversitesi Bilimsel Araştırma Projeleri tarafından desteklenmiştir (Proje no: 2015/3-3 YLS).

\section{KAYNAKLAR}

[1] İ. Akyüz, "Mobilya satın almada tüketici davranışlarını etkileyen psikolojik, sosyo-psikolojik ve sosyo-kültürel faktörlerin incelenmesi" Doktora tezi, Fen Bilimleri Enstitüsü, Karadeniz Teknik Üniversitesi, Trabzon, Türkiye, 2006.

[2] Ü. Yurdakul, M. Çolak ve T. Çetin, "Mobilya endüstrisinde kullanılan hammaddeler ve tedarikinde karş1laş1lan sorunlar," Kastamonu Üniversitesi Orman Fakültesi Dergisi, c. 13, s: 2, ss. 220-227, 2013.

[3] N. N. Yılmaz, "Türkiye ev mobilyası sektörünün değer zinciri yaklaşımıyla incelenmesi," Uzmanlık tezi, T.C. Kalkınma Bakanlığı, 2014.

[4] T. Erdem, "Mobilya tarihine genel bakış ve art deco," Yüksek Lisans tezi, Fen Bilimleri Enstitüsü, İstanbul Kültür Üniversitesi, 2007. 
[5] Orta Karadeniz Kalkınma Ajansı. (2019, 15 Haziran). A ̆gaç ürünleri ve mobilya sektör raporu, 2013 [Çevrimiçi]. Erişim: https://www.oka.org.tr/assets/upload/dosyalar/94mobilya-sektorraporu_v2.pdf.

[6] A. B. Dalgakıran, "Üretim İşletmelerinde tedarik zinciri yönetimi yaklaşımı sorunları ve çözüm önerileri: Örnek uygulama," Yüksek Lisans tezi, Sosyal Bilimler Enstitüsü, Yaşar Üniversitesi, 2016.

[7] TOBB. (2019, 20 Eylül). Türkiye mobilya ürünleri meclisi sektör raporu, 2017 [Çevrimiçi]. Erişim: https://tobb.org.tr/Documents/yayinlar/2018/MobilyaSektorleriMeclisi.PDF.

[8] K. C. Akyüz, H. Serin, İ. Akyüz ve H. Cındık, "Doğu Karadeniz bölgesindeki orman ürünleri sanayi işletmelerinin hammadde tercihleri ve tedarik sorunları," Artvin Orman Fakültesi Dergisi, Kafkas Üniversitesi, s. 1-2, ss. 68-75, 2003.

[9] K. C. Akyüz, İ. Akyüz, H. Serin ve H. Cındık, "Batı Akdeniz bölgesinde yer alan orman ürünleri sanayi işletmelerinin ihracat problemleri," Süleyman Demirel Üniversitesi Orman Fakültesi Dergisi, c. A, s. 1, ss. 97-110, 2004.

[10] K.C. Akyüz, C. Külahlı, İ. Yıldırım ve Y. Balaban, "Using of advanced manufacturing technologies in forest products industry enterprises in İnegöl," Turkish Journal of Forestry, s. 14, ss. 113-120, 2013.

[11] K.C. Akyüz, T. Gedik, ve İ. Akyüz, "Trabzon Arsin organize sanayi bölgesinde yer alan işletmelerinin rekabet stratejileri ve kalite anlayışları," Karadeniz Teknik Üniversitesi Uluslararası İktisadi ve İdari Incelemeler Dergisi, c. 2, s. 4, ss. 65-82, 2010.

[12] İ. Yıldırım, K.C. Akyüz, T. Gedik, Y. Balaban, ve Y. Çabuk, "Türkiye ahşap levha endüstrisinin Avrupa Birliği ülkeleri ile rekabet edebilirliği," Zonguldak Karaelmas Üniversitesi Bartın Orman Fakültesi Dergisi, c. 10, s. 13, ss. 11-22, 2008. 